\title{
ANALISIS DAN PERANCANGAN APLIKASI E-LEARNING BERBASIS GAMIFICATION (STUDI KASUS PROGRAM STUDI SISTEM INFORMASI INSTITUT TEKNOLOGI KALIMANTAN)
}

\author{
M. Gilvy Langgawan Putra*1, Hemy Octantia \\ 1,2Program Studi Sistem Informasi, Institut Teknologi Kalimantan \\ Email: 1 gilvy.langgawan@lecturer.itk.ac.id, ${ }^{2} 10171033 @$ student.itk.ac.id \\ *Penulis Konferensi
}

(Naskah masuk: 17 November 2020, diterima untuk diterbitkan: 09 Juni 2021)

\begin{abstract}
Abstrak
Pembelajaran pada institusi pendidikan khususnya perguruan tinggi pada era teknologi ini sebagian besar telah memanfaatkan penggunaan teknologi, seperti penggunaan power point untuk menyajikan materi dan penggunaan google classroom untuk memudahkan penyampaian berbagai file materi dan tugas. Walaupun telah menggunakan bantuan teknologi, terkadang kegiatan pembelajaran tetap dirasa membosankan bagi mahasiswa sehingga membuat motivasi belajar mahasiswa menurun. Tujuan dari penelitian ini adalah merancang sebuah aplikasi pembelajaran online atau e-learning berbasis gamification yang dapat meningkatkan motivasi belajar mahasiswa. Perancangan aplikasi dilakukan dengan metode pengembangan waterfall hingga tahap modelling. Perancangan e-learning diterapkan untuk pembagian materi, tugas, dan pelaksanaan ujian. Beberapa elemen gamification yang diterapkan pada perancangan aplikasi ini adalah challenge, reward, dan leaderboard. Sistem poin juga diterapkan pada fitur challenge dan pengguna dapat menukarkan poin tersebut dengan reward tertentu. Pada penelitian ini, dijelaskan bagaimana merancang sebuah aplikasi e-learning dengan metode gamification. Perancangan aplikasi pada penelitian ini menghasilkan 42 diagram use case, skenario use case, diagram sequence, class diagram, ERD, dan mock up aplikasi.
\end{abstract}

Kata kunci: e-learning, gamification, perancangan aplikasi

\section{GAMIFICATION BASED E-LEARNING APPLICATION ANALYSIS AND DESIGN (CASE STUDY OF INFORMATION SYSTEM STUDY PROGRAM IN KALIMANTAN INSTITUTE OF TECHNOLOGY)}

\begin{abstract}
Learning in educational institutions, especially universities in this technological era, has mostly taken advantage of the use of technology, such as the use of power points to present material and the use of google classrooms to facilitate the delivery of various material files and assignments. Even though they have used technology assistance, sometimes learning activities are still considered boring for students, so that students' learning motivation decreases. The purpose of this research is to design an online learning application or e-learning based on gamification which can increase student motivation. The application design is carried out using the waterfall development method to the modeling stage. The e-learning design is applied for the distribution of materials, assignments and exams. Some of the gamification elements applied to the design of this application are the challenges, rewards, and leaderboards. The point system is also applied to the challenge feature and users can exchange these points for certain rewards. In this paper, how to design an e-learning application with the gamification method will be explained. Application design in this paper developing 42 use case diagram, use case scenarios, sequence diagrams, class diagram, ERD, and application mock ups.
\end{abstract}

Keywords: e-learning, gamification, application design

\section{PENDAHULUAN}

Kegiatan pembelajaran merupakan kegiatan utama pada sebuah institusi pendidikan seperti Institut Teknologi Kalimantan. Kegiatan pembelajaran pada saat ini telah banyak dilakukan dengan bantuan teknologi, mulai dari penggunaan power point untuk menyajikan materi yang lebih menarik hingga penggunaan google classroom untuk 
memudahkan penyampaian berbagai file materi dan tugas.

Penggunaan google classroom pada pembelajaran merupakan salah satu contoh penerapan e-learning. E-learning adalah sebuah proses pembelajaran berbasis elektronik yang memanfaatkan jaringan komputer sebagai medianya (Pradana \& Priyambadha, 2018). Penggunaan $e$ learning memiliki manfaat yaitu pembelajaran menjadi lebih fleksibel karena dapat dilakukan tanpa harus dengan tatap muka.

Walaupun telah dilaksanakan dengan bantuan teknologi, kegiatan belajar mengajar tetap dirasa membosankan dan membuat motivasi belajar mahasiswa menurun. Berdasarkan survei yang telah dilakukan terhadap 37 mahasiswa program studi Sistem Informasi Institut Teknologi Kalimantan, 20 mahasiswa diantaranya $(70,3 \%)$ memiliki motivasi belajar yang rendah.

Untuk meningkatkan minat dan motivasi belajar mahasiswa, penggunaan e-learning dapat dipadukan dengan metode gamification. Tujuan dari penelitian ini adalah merancang aplikasi e-learning berbasis gamification untuk program studi Sistem Informasi Institut Teknologi Kalimantan.

\section{METODE PENELITIAN}

Metode penelitian yang digunakan mengacu pada metode waterfall pada tinjauan pustaka, namun hanya dilakukan hingga tahap modelling untuk perancangan aplikasi. Adapun tahapan metode dapat dilihat pada gambar 1 .

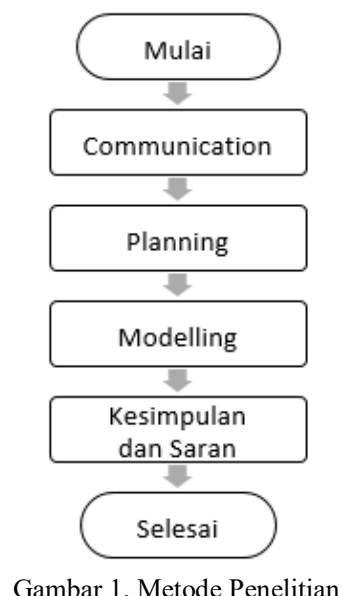

Penjelasan metodologi penelitian diatas yaitu sebagai berikut:

1. Communication

Tahap communication adalah tahap pengumpulan kebutuhan sistem. Tahap ini dilakukan dengan wawancara terhadap stakeholder untuk mendapatkan informasi mengenai sistem yang akan dirancang.

2. Planning

Tahap planning merupakan tahap perencanaan perancangan sistem. Pada tahap ini, lamanya waktu yang dibutuhkan untuk merancang sistem di estimasikan. Jadwal pengerjaan perancangan sistem juga dibuat agar perancangan sistem dapat dikerjakan sesuai waktu yang telah di estimasikan.

3. Modelling

Tahap modelling merupakan tahap analisis sistem dan desain sistem. Dalam tahap modelling, analisis dilakukan terhadap informasi-informasi yang telah didapatkan pada tahap communication untuk menentukan fitur sistem. Berbagai diagram seperti diagram use case, class diagram, sequence diagram, entity relationship diagram, dan mock up juga dibuat untuk menggambarkan sistem yang dirancang.

4. Kesimpulan dan Saran

Tahap terakhir yaitu menarik kesimpulan dan saran berdasarkan perancangan sistem yang telah dibuat pada tahap-tahap sebelumnya.

\section{TINJAUAN PUSTAKA}

\subsection{E-Learning}

E-learning adalah sebuah proses pembelajaran elektronik yang memanfaatkan jaringan komputer sebagai medianya. E-learning memungkinkan pengajar dan peserta didik untuk dapat melakukan pembelajaran dimanapun tanpa harus berkumpul di suatu ruangan tertentu (Pradana \& Priyambadha, 2018).

Pembelajaran pada perguruan tinggi semakin banyak dilakukan dengan e-learning. E-learning di perguruan tinggi memiliki ciri khas tersendiri. Karakteristik e-learning di perguruan tinggi yang diturunkan dari mahasiswa adalah: usia, karakteristik demografi, bidang studi, kompleksitas, dan lainnya (Urh, et al., 2015).

E-learning dapat digunakan sebagai media penyimpanan materi pembelajaran, forum, dan ujian, baik melalui ujian daring maupun penyerahan tugas (Pramukantoro \& Yahya, 2016). Proses pembelajaran dapat berlangsung dengan lebih fleksibel menggunakan e-learning. Namun disisi lain, e-learning mengakibatkan kurangnya interaksi antara dosen dengan peserta didik sehingga kemandirian peserta didik merupakan faktor yang perlu diperhatikan dalam keberhasilan e-learning.

\subsection{Gamification}

Gamification adalah proses menggunakan elemen dari game pada suatu bidang untuk membuatnya menjadi lebih menarik, mudah dipahami, dan kreatif (Pradana \& Priyambadha, 2018). Gamification juga dapat diartikan sebagai proses mengubah aktivitas dalam konteks non-game menjadi lebih menyerupai game dengan menggunaken elemen-elemen game. Ide utama dari gamification adalah untuk memanfaatkan potensi motivasi dari video game dengan menggunakan 
elemen game dalam lingkungan non-game (Sailer, et al., 2017). Penggunaan elemen dari sebuah game dapat menjadi cara yang tepat untuk meningkatkan motivasi peserta didik dan meningkatkan efektivitas pendidikan pada e-learning (Bernik, et al., 2017). Gamification telah banyak digunakan pada berbagai bidang seperti pada e-learning, e-commerce, aplikasi perangkat lunak, dan lain sebagainya.

Terdapat enam elemen game yang memungkinkan untuk diterapkan pada e-learning antara lain badge, reward, point, timer, level, dan leaderboard (Alshammari, 2019). Penjelasan setiap elemen game dapat dilihat pada tabel 1 .

\begin{tabular}{|c|c|}
\hline Elemen Game & Deskripsi \\
\hline Badge & $\begin{array}{ll}\text { Lambang khusus yang } \\
\text { diberikan kepada peserta didik } \\
\text { saat menyelesaikan tugas } \\
\text { tertentu. }\end{array}$ \\
\hline Reward & $\begin{array}{l}\text { Imbalan yang akan diberikan } \\
\text { kepada peserta didik setelah } \\
\text { berhasil menyelesaikan tugas } \\
\text { tertentu. }\end{array}$ \\
\hline Point & \begin{tabular}{lr}
\multicolumn{3}{l}{ Peserta didik akan mendapatkan } \\
poin berdasarkan kemajuan \\
peserta didik \\
pembelajaran.
\end{tabular} \\
\hline Timer & $\begin{array}{l}\text { Beberapa tugas maupun ujian } \\
\text { pembelajaran memiliki } \\
\text { pengaturan waktu dan peserta } \\
\text { didik harus menyelesaikan } \\
\text { dalam waktu yang tersedia. }\end{array}$ \\
\hline Level & $\begin{array}{l}\text { Posisi peserta didik berdasarkan } \\
\text { kemajuan belajar masing- } \\
\text { masing peserta didik. }\end{array}$ \\
\hline Leaderboard & $\begin{array}{l}\text { Papan peringkat yang } \\
\text { menampilkan nama peserta } \\
\text { didik dari nilai yang tertinggi. }\end{array}$ \\
\hline
\end{tabular}

\subsection{Metode Waterfall}

Metode Waterfall merupakan metode pengembangan perangkat lunak yang paling sederhana dan sering disebut sebagai classic life cycle (siklus hidup klasik). Tahapan metode waterfall dapat dilihat pada gambar 2 .

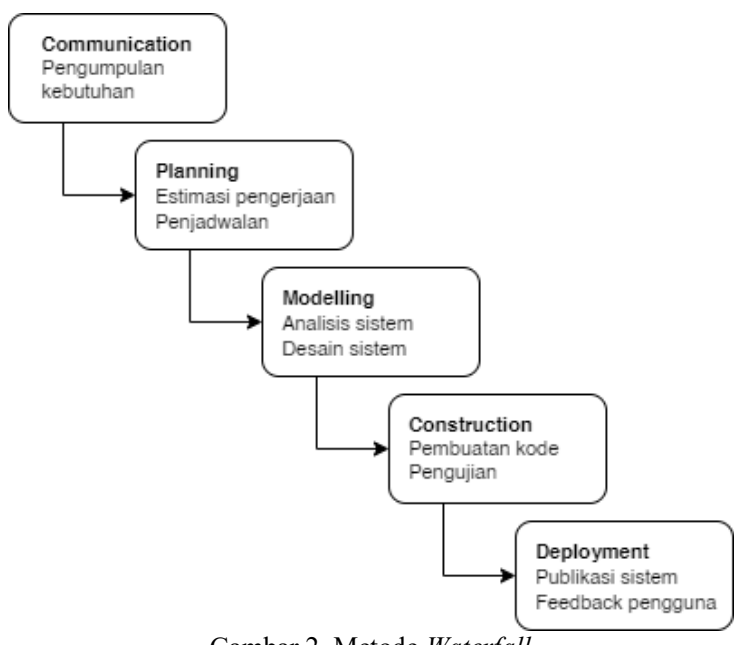

Gambar 2. Metode Waterfall
Menurut Kustian (2019), metode waterfall terdiri dari 5 tahap sebagai berikut:

\section{Communication}

Tahap communication merupakan tahap pertama dalam metode waterfall. Pada tahap ini, seluruh kebutuhan dan data-data yang diperlukan dalam pengembangan perangkat lunak dikumpulkan.

\section{Planning}

Tahap planning merupakan tahap untuk perencanaan pengembangan perangkat lunak, mulai dari estimasi waktu pengembangan perangkat lunak hingga penjadwalan pengembangan perangkat lunak.

3. Modelling

Pada tahap modelling dibuat berbagai diagram yang dapat menggambarkan cara kerja sistem, tampilan sistem, dan algoritma sistem.

\section{Construction}

Tahap construction merupakan tahap untuk mengubah desain sistem yang telah dibuat pada tahap sebelumnya menjadi baris-baris kode. Pengujian kode sistem juga dilakukan pada tahap ini.

5. Deployment

Tahap deployment merupakan tahap untuk mempublikasikan perangkat lunak yang telah dibuat kepada pengguna.

\subsection{Use Case Diagram}

Diagram use case adalah sebuah diagram yang merepresentasikan interaksi antara pengguna (aktor) dengan sebuah sistem. Terdapat 2 elemen penting dalam diagram use case yaitu aktor dan use case. Aktor merupakan orang yang berinteraksi langsung dengan sistem atau aplikasi, sedangkan use case merupakan gambaran interaksi aktor dengan sistem (Kurniawan, 2018).

Diagram use case memiliki simbol-simbol yang dapat dilihat pada tabel 2.

Tabel 2. Simbol Diagram Use Case

\begin{tabular}{|c|c|}
\hline Simbol & Keterangan \\
\hline Aktor & $\begin{array}{lr}\text { Pengguna yang berinteraksi } \\
\text { dengan sistem. Aktor } \\
\text { ditunjukkan dengan nama } \\
\text { perannya dalam sistem }\end{array}$ \\
\hline Use Case & $\begin{array}{l}\text { Gambaran dari interaksi } \\
\text { antara aktor dengan sistem. }\end{array}$ \\
\hline Asosiasi & $\begin{array}{l}\text { Menggambarkan interaksi } \\
\text { aktor dan use case secara } \\
\text { langsung. }\end{array}$ \\
\hline Include & $\begin{array}{l}\text { Menggambarkan fungsi } \\
\text { sebuah use case yang hanya } \\
\text { dapat dipenuhi dengan } \\
\text { bantuan dari use case yang } \\
\text { lainnya }\end{array}$ \\
\hline
\end{tabular}




\begin{tabular}{cl}
\hline Simbol & \multicolumn{1}{c}{ Keterangan } \\
\hline \multirow{2\text{Extends>}}{\text{Extend}}{} & $\begin{array}{l}\text { Menggambarkan fungsi } \\
\text { sebuah use case yang dapat } \\
\text { diperluas oleh use case lain, } \\
\text { jika dibutuhkan }\end{array}$ \\
\hline Inheritance & $\begin{array}{l}\text { Relasi antara suatu aktor } \\
\text { dengan aktor turunannya. }\end{array}$
\end{tabular}

\subsection{Use Case Scenario}

Skenario use case adalah penjelasan dari setiap use case dalam diagram use case. Setiap skenario use case dapat menjelaskan tahapan aksi atau langkah yang dilakukan oleh aktor ketika menggunakan sistem. Skenario use case biasanya dijelaskan dalam bentuk tabel (Kurniawan, 2018). Terdapat beberapa bagian penting pada skenario use case, yaitu:

a. Aktor Primer (Primary Actor)

Pengguna yang mengakses sistem untuk memenuhi tujuannya. Aktor primer dapat berjumlah lebih dari 1.

b. Prakondisi (Preconditions)

Suatu kondisi yang harus dipenuhi sebelum aktor menjalankan sebuah use case. Prakondisi dapat berjumlah lebih dari 1 keadaan.

c. Alur Utama (Main Flow)

Jalur interaksi utama yang berisi tahapan untuk memenuhi tujuan aktor dalam suatu use case. Setiap use case hanya memiliki 1 alur utama.

d. Alur Alternatif (Alternative Flow)

Jalur alternatif yang dapat ditempuh aktor selain alur utama. Setiap use case dapat memiliki lebih dari 1 alur alternatif.

e. Kondisi Akhir (Postconditions)

Kondisi yang terpenuhi saat sebuah use case telah selesai dijalankan. Kondisi akhir dapat berjumlah lebih dari 1 keadaan.

\subsection{Class Diagram}

Class diagram adalah suatu diagram yang dapat menggambarkan variabel atau atribut suatu kelas pada sistem beserta metode yang dapat dilakukan oleh kelas tersebut. Metode (methods) merupakan proses sistem dalam mengelola data yang dimiliki sistem tersebut (Hendy, 2019). Contoh class diagram beserta notasinya dapat dilihat pada gambar 3.

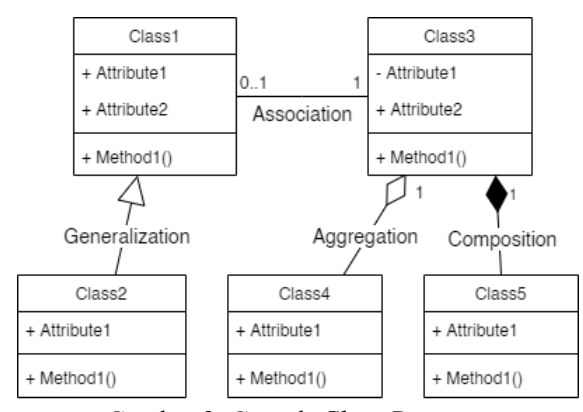

Gambar 3. Contoh Class Diagram

\subsection{Entity Relationship Diagram (ERD)}

Entity relationship diagram (ERD) merupakan suatu diagram yang menggambarkan hubungan dari suatu objek data atau entitas ke entitas lainnya. Elemen-elemen penting pada ERD yaitu entitas (bentuk nyata atau abstrak dari suatu data dengan karakteristik tertentu), atribut (ciri-ciri dari entitas tertentu), dan relasi (hubungan antar entitas) (Fridayanthie \& Mahdiati, 2016). Contoh ERD dapat dilihat pada gambar 4 .

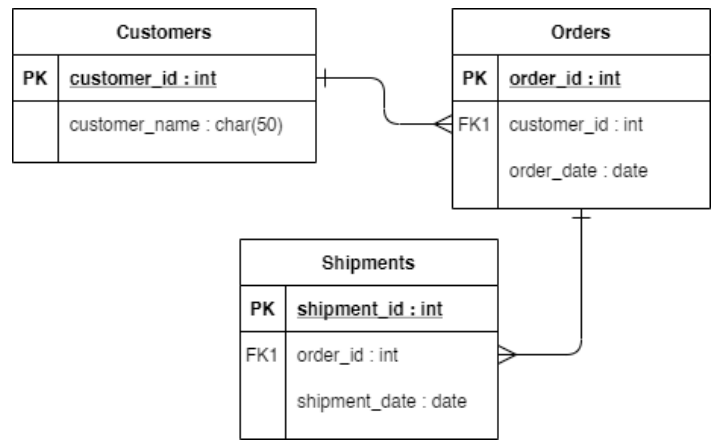

Gambar 4. Contoh Entity Relationship Diagram

\section{HASIL DAN PEMBAHASAN}

Elisitasi kebutuhan dilakukan sebelum perancangan aplikasi. Elisitasi kebutuhan dilakukan dengan wawancara terhadap dosen dan penyebaran kuesioner kepada mahasiswa untuk mengetahui permasalahan yang terjadi dan fitur apa yang diperlukan untuk menyelesaikan masalah tersebut. Permasalahan yang terjadi pada studi kasus adalah rendahnya motivasi belajar mahasiswa. Berdasarkan survei yang telah dilakukan, 70,3\% responden menyatakan memiliki motivasi belajar rendah. Sedangkan untuk yang memiliki motivasi belajar tinggi hanya 29,7\%. Untuk mengatasi permasalahan tersebut, maka dirancanglah sebuah aplikasi $e$ learning berbasis gamification untuk program studi Sistem Informasi Institut Teknologi Kalimantan dengan nama ESIKA. Faktor lain yang juga diperhatikan dalam perancangan aplikasi ESIKA adalah karakteristik mahasiswa SI ITK yang sebagian besar memiliki hobi bermain game.

Aplikasi ESIKA memiliki 5 fitur utama yaitu sebagai berikut:

a. Sistem mampu memberikan fitur membuat kelas yang dapat digunakan dosen untuk mengunggah materi, tugas, dan ujian.

b. Sistem mampu memberikan fitur buat materi dan tugas untuk dosen serta fitur unggah jawaban tugas untuk mahasiswa.

c. Sistem mampu memberikan fitur membuat ujian untuk dosen serta fitur mengikuti ujian untuk mahasiswa.

d. Sistem mampu memberikan fitur-fitur gamification yang dapat meningkatkan motivasi mahasiswa seperti challenge dan reward. 
e. Sistem mampu menampilkan ranking nilai mahasiswa pada setiap kelas.

Terdapat 4 aktor yang terlibat dalam aplikasi ESIKA yaitu pengguna umum, dosen, mahasiswa, dan admin. Dosen berperan untuk membuat kelas, materi, tugas, ujian, challenge, dan reward. Mahasiswa berperan untuk melihat materi, menjawab tugas, ujian, challenge, dan mengambil reward. Admin berperan untuk mengelola pengguna yang dapat mengakses ESIKA. Dan pengguna umum adalah generalisasi dari 3 aktor lainnya untuk proses login, daftar, dan lupa password.

Elemen game yang diterapkan pada aplikasi ESIKA adalah challenge, reward, dan leaderboard. Elemen challenge diterapkan dalam bentuk pertanyaan tambahan yang dapat diikuti oleh mahasiswa diluar tugas dan quiz. Challenge tidak terbatas oleh kelas sehingga mahasiswa dari semua kelas dapat mengikuti challenge untuk mendapatkan poin. Poin selanjutnya dapat ditukar dengan reward tertentu jika memenuhi persyaratan reward yang telah ditentukan. Reward yang dapat ditukar yaitu berupa nilai tambahan untuk kelas tertentu maupun reward lainnya yang telah dibuat oleh dosen. Sedangkan untuk leaderboard diterapkan dalam bentuk ranking nilai mahasiswa pada setiap kelas.

Adapun diagram use case aplikasi ESIKA dapat dilihat pada gambar 5 .

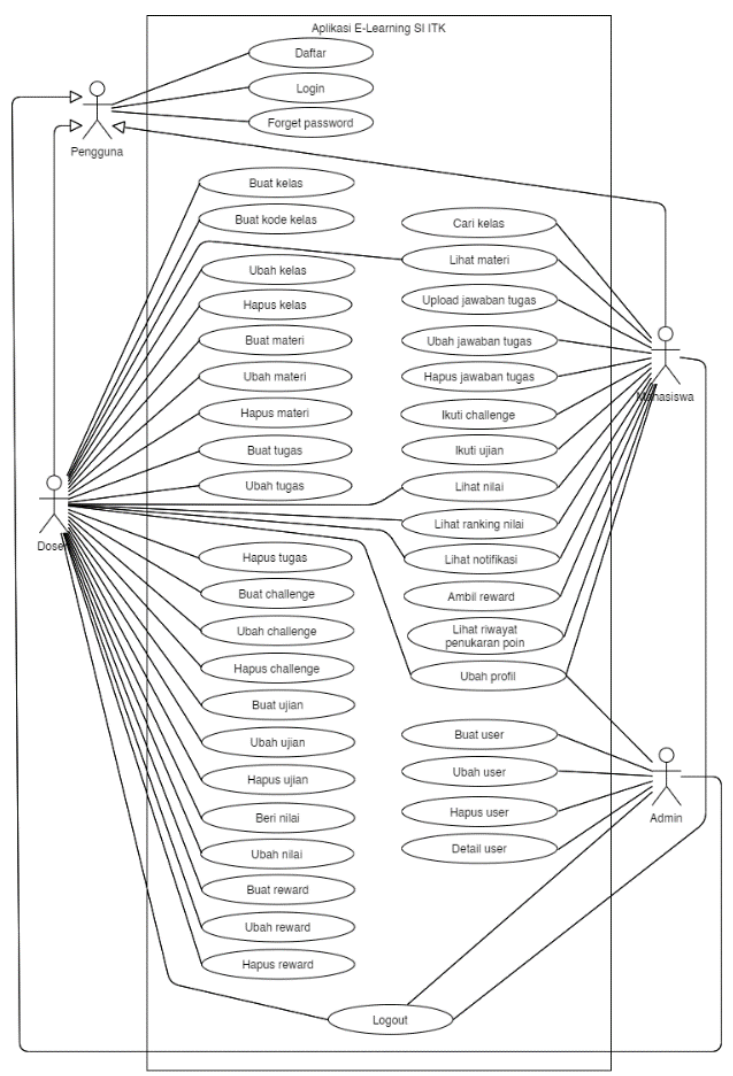

Gambar 5. Diagram Use Case ESIKA

Beberapa skenario use case dari diagram use case diatas dapat dilihat pada tabel 3 dan 4 .
Tabel 3. Skenario Use Case Login

\begin{tabular}{ll}
\hline Nama Usecase & Login \\
\hline Aktor & Pengguna umum \\
\hline Deskripsi & $\begin{array}{l}\text { Dapat masuk ke sistem sesuai hak } \\
\text { akses }\end{array}$ \\
\hline Pre-kondisi & Berada pada halaman login \\
\hline Main Flow & 1 Memasukkan email dan password \\
& 2 Memilih tombol 'login' \\
\hline Alternative flow & $\begin{array}{l}\text { 1 Jika data tidak valid saat } \\
\text { melakukan login maka akan } \\
\text { dan kembali menginputkan email } \\
\text { dan password }\end{array}$ \\
\hline Post-kondisi & $\begin{array}{l}\text { Berhasil login, sistem menampilkan } \\
\text { halaman dashboard }\end{array}$ \\
\hline
\end{tabular}

Tabel 4. Skenario use case ambil reward

\begin{tabular}{ll}
\hline Nama Usecase & Ambil reward \\
\hline Aktor & Mahasiswa \\
\hline Deskripsi & $\begin{array}{l}\text { Dapat mengambil reward dengan } \\
\text { menukarkan sejumlah poin }\end{array}$ \\
\hline Pre-kondisi & $\begin{array}{l}\text { Memiliki poin yang cukup, berada } \\
\text { pada halaman dashboard }\end{array}$ \\
\hline & 1 Memilih 'reward' \\
& 2 Memilih salah satu reward \\
Main Flow & 3 Membaca detail reward \\
& 4 Klik 'ambil reward' \\
\hline Alternative flow & - Jumlah poin pengguna berkurang \\
\hline Post-kondisi & Berhasil mengambil reward \\
\hline
\end{tabular}

Sequence diagram dibuat untuk mengetahui alur informasi yang diproses oleh sistem. Adapun sequence diagram dari 2 skenario use case diatas dapat dilihat pada gambar 6 dan 7 .

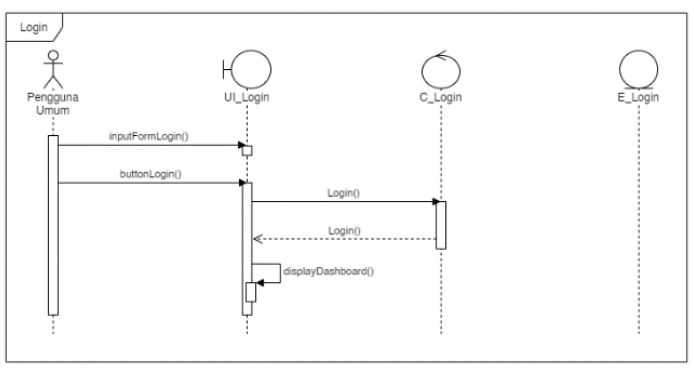

Gambar 6. Sequence Diagram Login

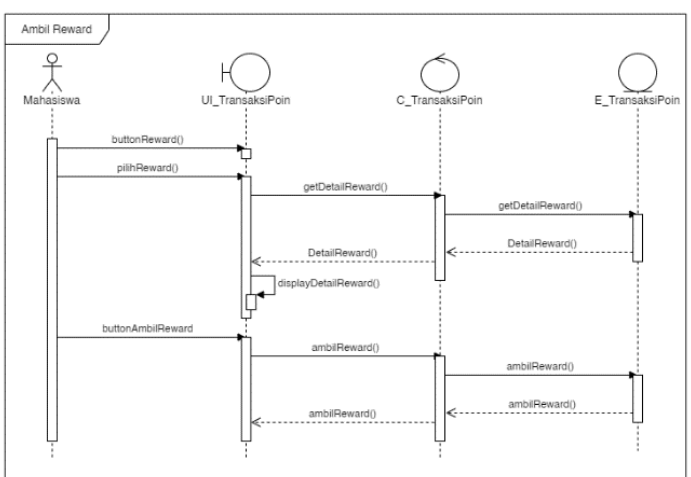

Gambar 7. Sequence Diagram Ambil Reward

Pada perancangan aplikasi ESIKA juga dibuat class diagram untuk menggambarkan kelas-kelas beserta relasi antar kelas-kelas tersebut. Adapun class diagram ESIKA dapat dilihat pada gambar 8. 


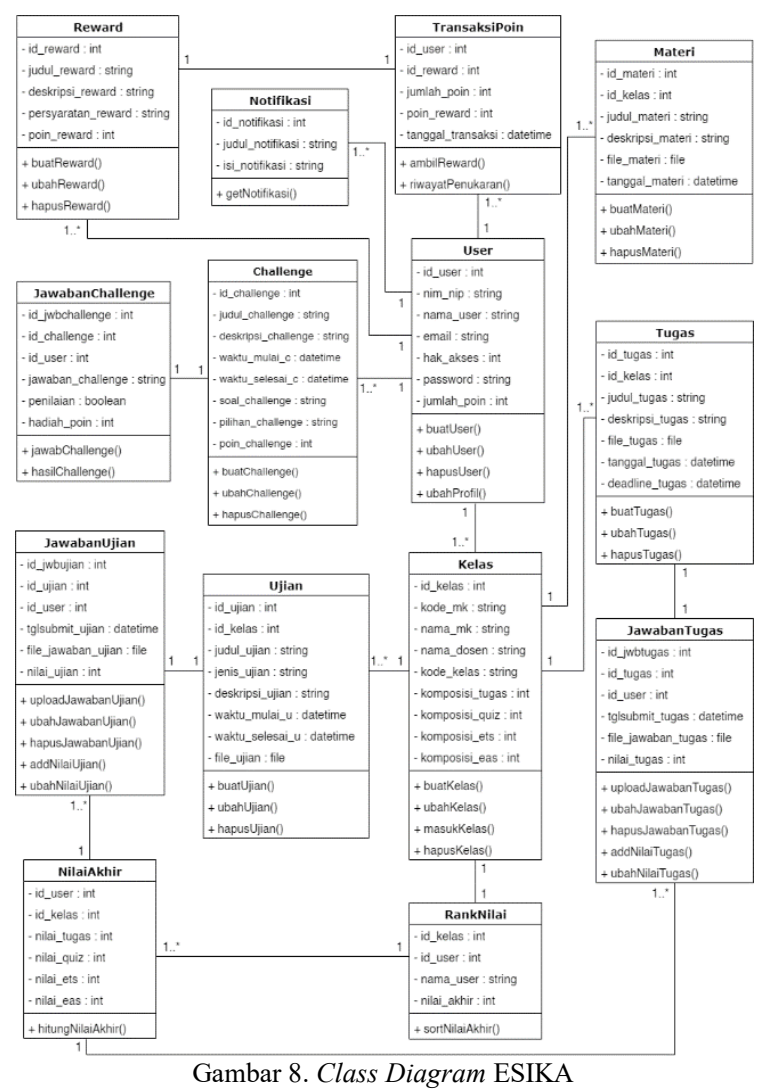

Pemodelan menggunakan ERD juga dilakukan pada perancangan aplikasi ini untuk menggambarkan entitas-entitas yang dibutuhkan pada database sistem serta relasinya. Adapun ERD aplikasi ESIKA dapat dilihat pada gambar 9.

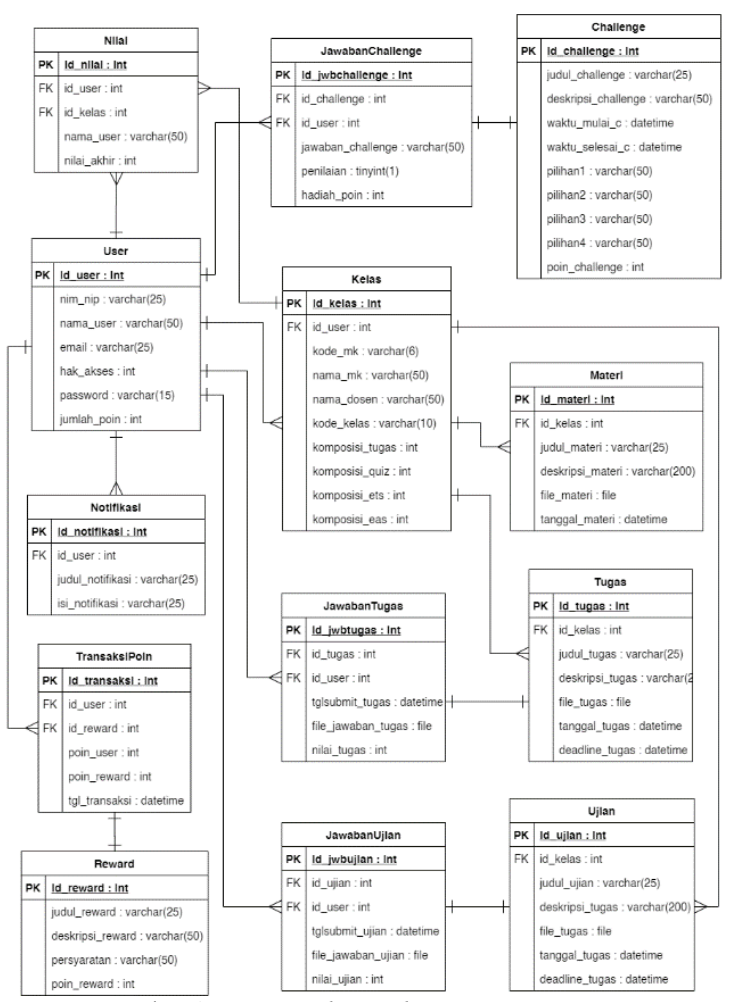

Gambar 9. Entity Relationship Diagram ESIKA
Terakhir, pembuatan mock up atau tampilan sistem juga dibuat. Pembuatan mock up ini bertujuan untuk menggambarkan tampilan aplikasi yang akan digunakan oleh pengguna. Adapun tampilan aplikasi ESIKA dapat dilihat pada gambar 10 hingga gambar 15.
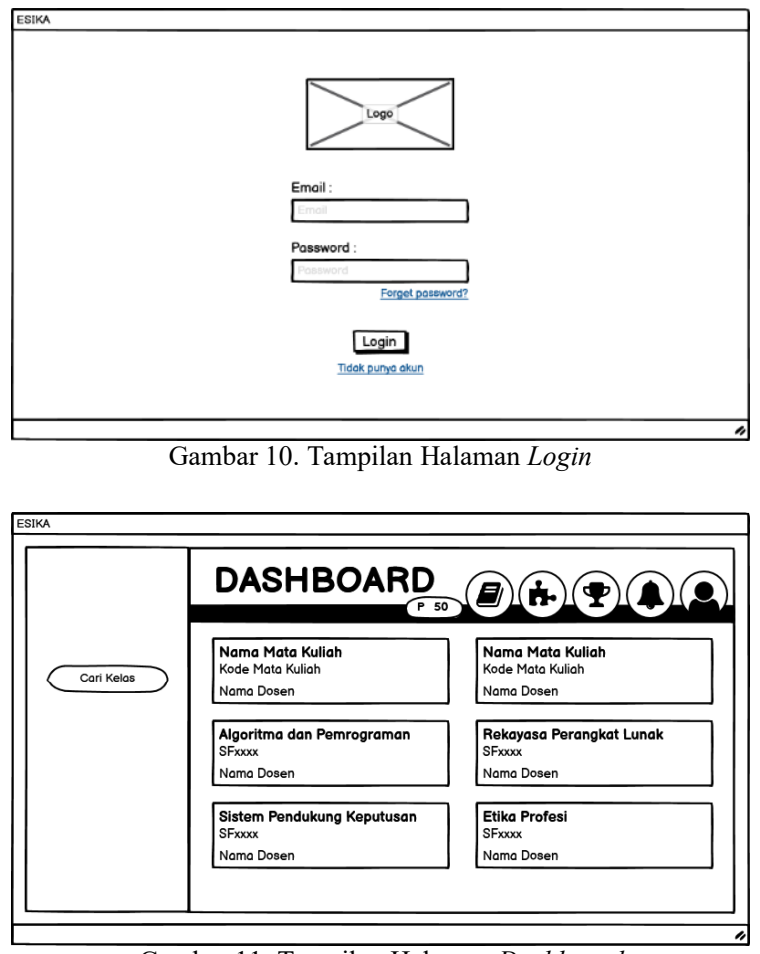

Gambar 11. Tampilan Halaman Dashboard
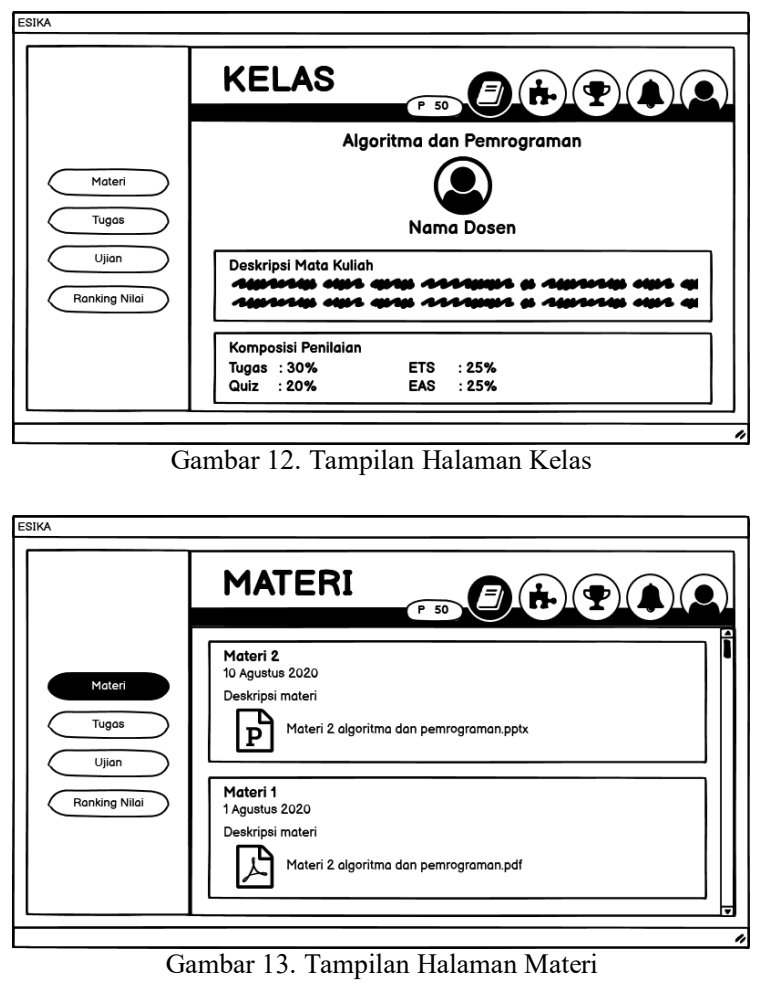


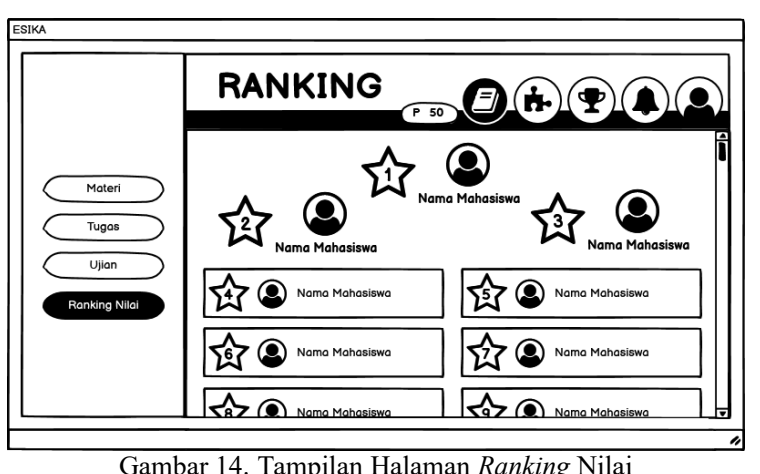

Gambar 14. Tampilan Halaman Ranking Nilai

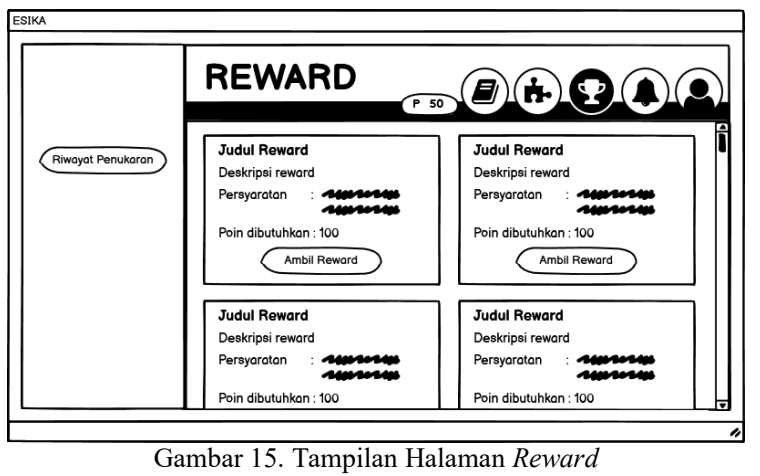

\section{KESIMPULAN DAN SARAN}

\subsection{Kesimpulan}

Kesimpulan yang dapat diambil berdasarkan penelitian yang telah dilakukan adalah sebagai berikut:

1. Aplikasi ESIKA dirancang dengan menggunakan beberapa elemen game seperti challenge, reward, dan leaderboard (ranking nilai) untuk meningkatkan motivasi belajar mahasiswa.

2. Hasil dari analisis perancangan ini menghasilkan beberapa kebutuhan yang terdiri dari 42 use case, scenario use case, diagram sequence, class diagram, ERD, dan mock up aplikasi.

\subsection{Saran}

Saran yang dapat diambil untuk meningkatkan penelitian yang telah dilakukan adalah sebagai berikut:

1. Perancangan aplikasi ESIKA hanya sampai pada tahap pembuatan mock up aplikasi sehingga selanjutnya dapat disempurnakan dengan pembangunan aplikasi sesuai dengan rancangan yang telah dibuat.

2. Elemen game pada aplikasi ESIKA dapat ditambahkan dengan elemen game yang lain seperti level, badge, maupun timer agar aplikasi lebih menarik.

\section{DAFTAR PUSTAKA}

ALSHAMMARI, M. T., 2019. Design and Learning Effectiveness Evaluation of Gamification in e-Learning Systems. International Journal of Advanced Computer Science and Applications, 10(9), pp. 204-208.

BERNIK, A., RADOŠEVIĆ, D. \& BUBAŠ, G., 2017. Introducing Gamification into eLearning University Courses. MIPRO, pp. 711-716.

FRIDAYANTHIE, E. W. \& MAHDIATI, T., 2016. Rancang Bangun Sistem Informasi Permintaan ATK Berbasis Intranet (Studi Kasus: Kejaksaan Negeri Rangkasbitung). Jurnal Khatulistiwa Informatika.

HENDY, 2019. Pemodelan Sistem Menggunakan UML (Unified Modelling Language). Conference Paper: System Modelling.

KURNIAWAN, T. A., 2018. Pemodelan Use Case (UML): Evaluasi Terhadap Beberapa Kesalahan Dalam Praktik. Jurnal Teknologi Informasi dan Ilmu Komputer (JTIIK), pp. 77-86.

KUSTIAN, N., 2019. Penggunaan Model Waterfall dalam Pembuatan Aplikasi Pemesanan Tiket Bus. Satuan Tulisan Riset dan Inovasi Teknologi (STRING), Volume 4, pp. 94 104.

PRADANA, F. \& PRIYAMBADHA, B., 2018. Pengarun Elemen Gamification Terhadap Hasil Belajar Siswa pada E-Learning Pemrograman Java. Seminar Nasional Teknologi Informasi dan Multimedia.

PRAMUKANTORO, E. S. \& YAHYA, W., 2016. Belajardisini : The E-learning Framework Based on Gamification Concept. Journal of Information Technology and Computer Science (JITeCS), 1(1), pp. 38-43.

SAILER, M., HENSE, J. U., MAYR, S. K. \& MANDL, H., 2017. How Gamnification Motivates: An Experimental Study of the Effects of Specific Game Design Elements on Phychological Need Satisfaction. Elsevier - Computers in Human Behavior, pp. 371-380.

URH, M., VUKOVIC, G., JEREB, E. \& PINTAR, R., 2015. The Model for Introduction of Gamification Into E-learning in Higher Education. Procedia - Social and Behavioral Sciences, pp. 388-397. 
Halaman ini sengaja dikosongkan 